Size of Social Network and Probability of Occurrence of HIV/AIDS among Sexually Affected Patients in Behavioral Diseases Consulting Centers

\title{
Emma Avanessian ${ }^{1}$, Mohsen Naserirad $^{2}$, Hrant Abrahamian $^{3}$, Sarah Anis $^{1}$
}

1. Dept. of Social Sciences, Faculty of Humanities, École Normale Supérieure, Paris, France

2. Dept. of Sociology, Faculty of Social Sciences, University of Tehran, Tehran, Iran

3. Dept. of Epidemiology and Biostatics, School of Public Health, Tehran University of Medical Sciences, Tehran, Iran

Article Information

\section{Article History:}

Received: 2016/04/12

Accepted: 2017/04/22

Available online: 2017/08/18

\section{IJHEHP 2017; 5(2): 73-80}

DOI: $10.30699 /$ acadpub.ijhehp.5.2.1

\section{Corresponding Author:}

\section{Mohsen Naserirad}

Dept. of Sociology, Faculty of Social Sciences, University of Tehran, Tehran, Iran

\section{Tel: +989152583500}

\section{Email: naserirad@ut.ac.ir}

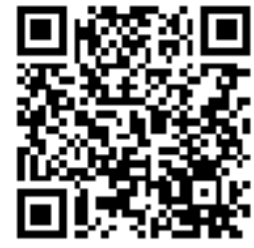

\section{Abstract}

Background and Objective: AIDS is a socio-medical problem and has vast consequences. To prevent the sexual affection it is necessary to detect the role of social determinants of health and social networks. This study was conducted to assess the association between size of social network and probability of occurrence of HIV/AIDS among sexually affected patients in behavioral diseases consulting centers covered by Shahid Beheshti University of medical sciences in 1394.

Methods: This research was a case-control study including 94 patients consulting the Shahid Beheshti University of Medical Sciences centers of AIDS as case group and 94 persons as control group in Tehran, Iran. Samples were selected by the classified method; the later sampling was done by the convenience sampling method. The tools for data collection were demographic questionnaires, as well as a questionnaire to obtain data on size of social network. Data were analyzed by SPSS.22 software and logistic regression analysis and discrimination analysis.

Results: Size of social network in sexual affected patients is smaller than nonaffected persons. There is a significant difference, and positive effect between sizes of social network in sexual affected and non-affected patients $(P<0 / 01)$. Size of family social network has the largest contribution in explanation of difference between the affected and non-affected patients. Findings showed that the bigger the size of their social network is, the less the probability of occurrence of HIV/AIDS is.

Conclusion: It is necessary to adjust sexual risk behaviors and detect the role of social network and sexual physio-psycho-social paths by which it transmitted.

KeyWords: AIDS, Risk Behaviors, Social Determinant of Health, Social Network, Sexually Affected Patients

Copyright () 2017 Iranian Journal of Health Education and Health Promotion. All rights reserved.

How to Cite This Article:

Avanessian E, Naserirad M, Abrahamian H, Anis S. Size of Social Network and Probability of Occurrence of HIV/AIDS among Sexually Affected Patients in Behavioral Diseases Consulting Centers. Iran J Health Educ Health Promot. 2017; 5(2):73-80.

Avanessian, E., Naserirad, M., Abrahamian, H. \& Anis, S. (2017). Size of Social Network and Probability of Occurrence of HIV/AIDS among Sexually Affected Patients in Behavioral Diseases Consulting Centers. Iranian Journal of Health Education and Health Promotion., 5(2):73-80. 


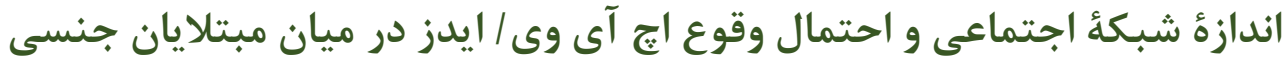

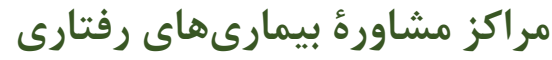
إِا آوانسيان'، محسن ناصرى راد'، هراند آبراهاميان"، سارا انيس'

1. كروه علوم اجتماعى، دانشكدة علوم انسانى، اكول نرمال سويريور، هاريس، فرانسه

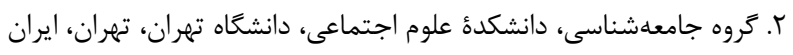

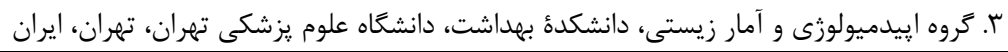

\section{جكبا:}

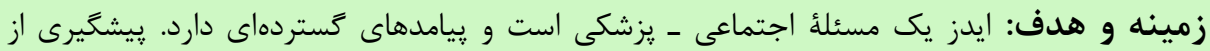

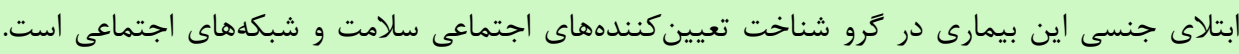

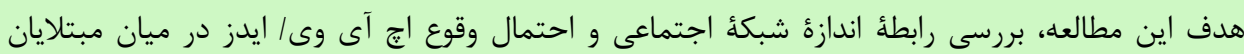

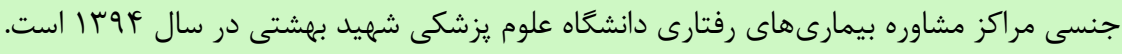
روش بررسى: يزوهش حاضر يك مطالعهُ توصيفى و مقطعى است. جمعيت آمارى شامل مبتلايان

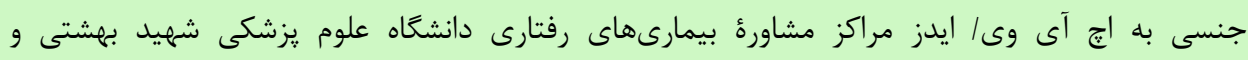

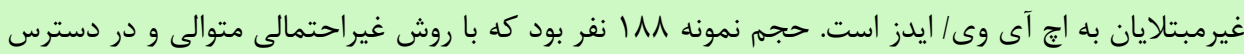

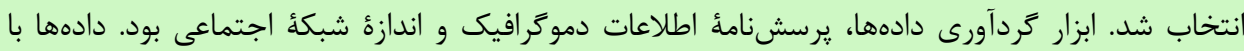

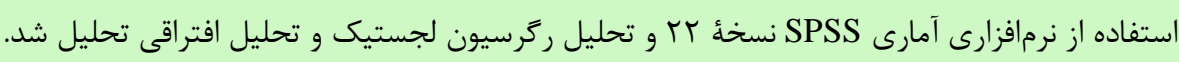

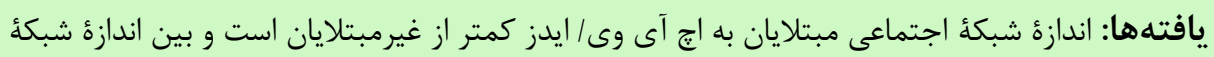

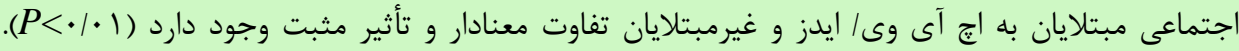

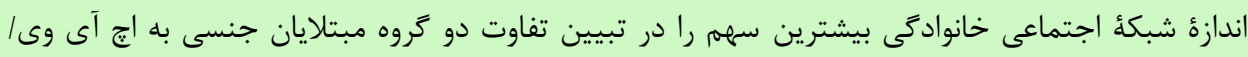

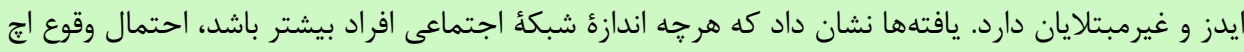
ایى وى/ ايدز كمتر است. نتيجه كيرى: شناخت ابعاد و اندازه شبكههاى اجتماعى و مسيرهاى جسمى - روانى ـ اجتماعى انتقال

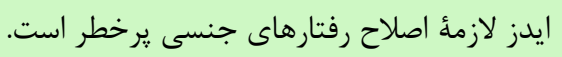

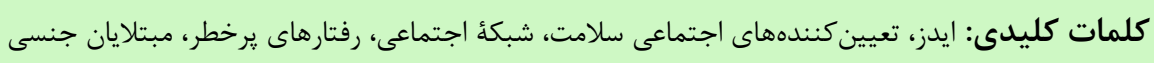
كبىرايت (؟) حق جاب، نشر و استفادة علمى از اين مقاله براى مجلهُ آموزش بهداشت و ارتقاى سلامت محفوظ است.
اطلاعات مقاله

ناريخجه مقاله

دريافت:

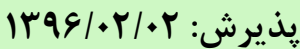

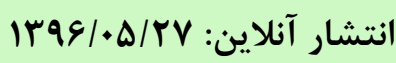

IJHEHP 2017; 5(2): 73-80

نويسنده مسئول:

زروه جامعهشناسى، دانشكده علوم اجتماعى، دانشعاه تهران، تهران، ايران

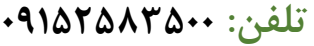
: بست الكترونيك:

naserirad@ut.ac.ir

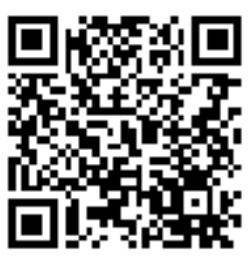

مرگومير انسان است (ه). براساس آمار سازمان ملل كه در سال

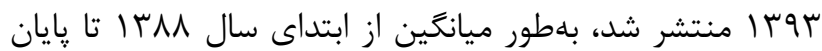

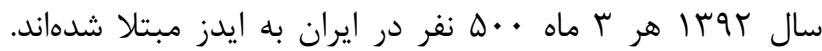

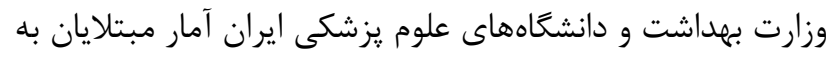

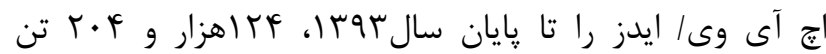
برآورد كردهاند كه NV درصد آنان را مردان و سا درصد را زنان تشكيل مىدهند. بنا به اين آمار، مب درصد مبتلايان به اين بيمارى از راه روابط جنسى مبتلا شدهاند (و). جوانان كه

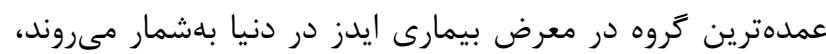

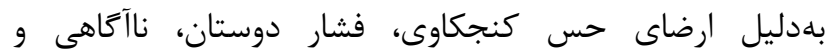

ايدز پديدهاى بهداشتى و يك مسئلة اجتماعى است (1) كه ييامدهاى روانى، فرهنگى، اقتصادى و جسمى آن بسيار گسترده است. در اوايل پيدايش بيمارى تصور بر آن بود كه به بيمارى

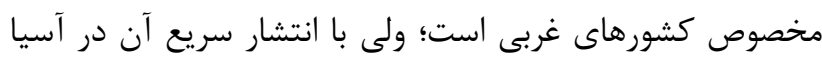
مشخص شد كه ايدز هيج قوم و نثاد و كشورى را در امان نخواهد گذاشت (ץ). امروزه ايدز در كشورهاى در حال توسعه بهسرعت در حال گسترش است كه تأثير قابل ملاحظهاى بر سلامت و

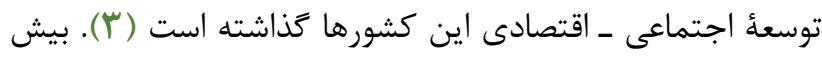
از • • درصد موارد ابتلاء مربوط به كشورهاى جهان سوم و در حال توسعه است (F). ايدز در حال حاضر جهارمين علت 
مبارزه با ايدز يك تعهد اجتماعى است و يِيشنياز اصلاح

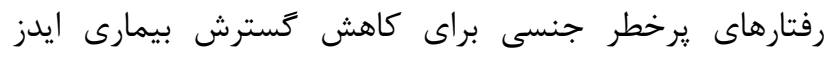

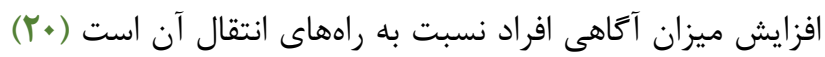
كه اين خود در كرو شناخت تعيين كنندهاى اجتماعى و فرهنكى اين بيمارى در كنار ساير عوامل زيستى است. در اين راستا انجام

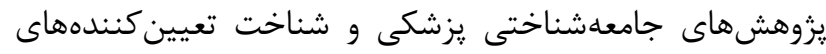
اجتماعى ايدز امكان دستيابى به شناخت بيشتر را فراهم مى بـآورد. هدف اين مطالعه، بررسى رابطهٔ اندازه شبكة اجتماعى و احتمال وقوع اج آى وى/ ايدز در ميان مبتلايان جنسى مراكز مشاوره بيمارىهاى رفتارى دانشكاه علوم يزشكى شهيد بهشتى است إن.

بهمنظور تبيين تأثير شبكههاى اجتماعى بر احتمال وقوع

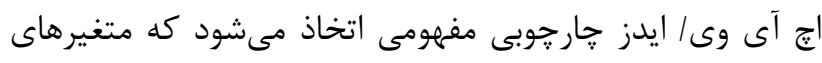

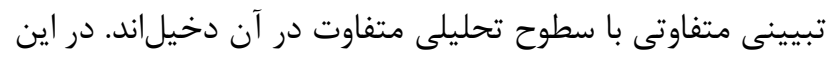

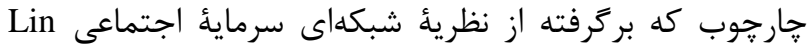
است (YlY)، بر تأثير شبكههاى اجتماعى در سطح فردى بر مبناى

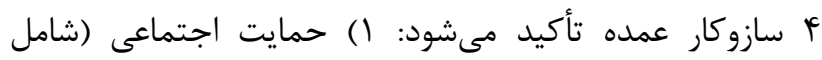

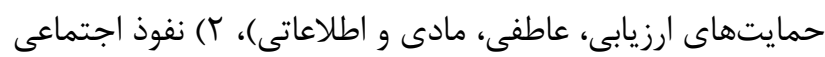

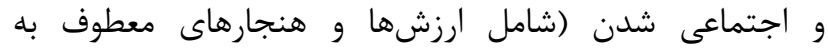

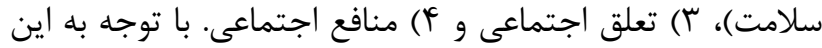

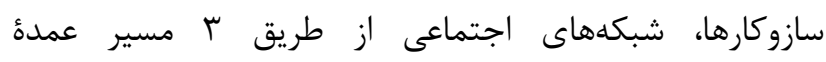
روانشناختى، رفتارى و فيزيولوزيك بر سلامت تأثير مى كذارند (Y (Y). در مسير روانشناختى، شبكههاى اجتماعى از طريق فراهم كردن دسترسى به منافع و حمايتهاى اجتماعى مختلف عامل عمدهاى در كاهش استرسهاى مزمن هستند. در مسير رفتارى،

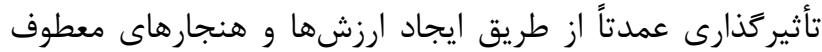

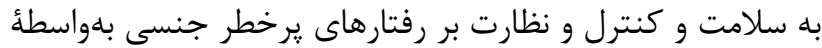

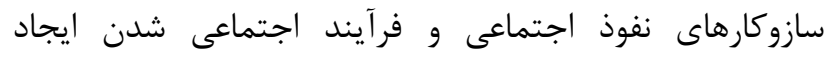

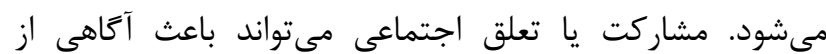

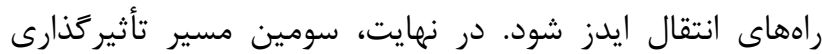

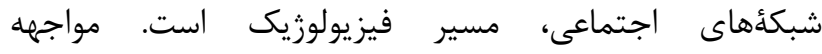
طولانىمدت در موقعيتهاى استرس زا مىتواند با ايجاد اختلال در نظام هورمونى - روانى، بهعنوان بخشى از واكنش زيستى

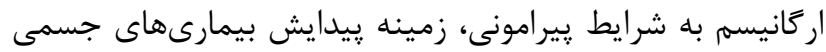

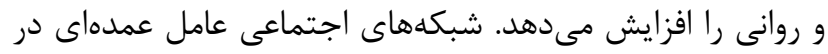
كاهش استرسهاى مزمن و جلوكيرى از فعال شدن سيستم هورمونى روانى و حفظ تعادل سيستم ايمنى بدن است.
بى بمهارتى با خطر تجربهُ جنسى غيرايمن روبهرو هستند و

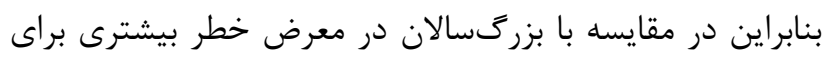

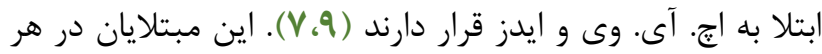

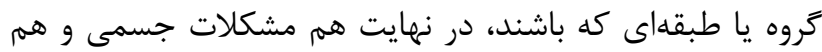
مشكلات روانى ـ اجتماعى خواهند داشت. آنان در مقابل

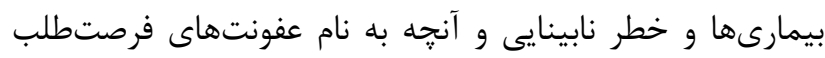

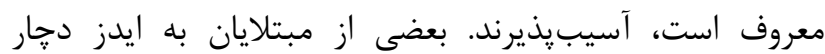

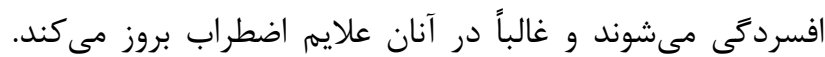
بهعلت پيشداورى و ترس از سرايت بيمارى ايدز، اين بيماران

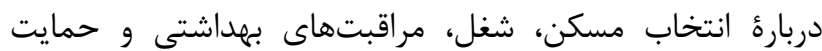
عمومى تحت تبعيض قرار مى ثيرند. رفتارهاى نامناسب و

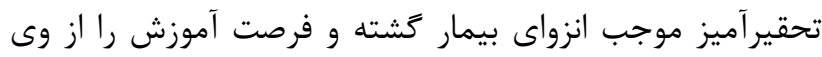

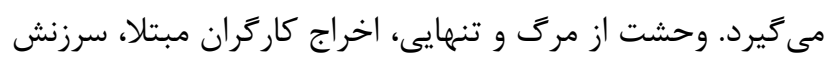

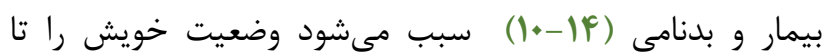
جايى كه مقدور است مخفى نغَه دارند كه اين خود موجب

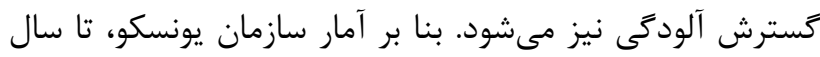

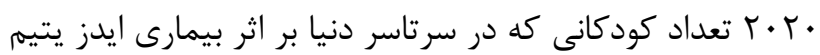

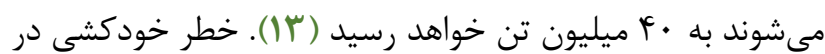
ميان مبتلايان به ايدز از مردم معمولى بيشتر است. مواجه شدن با بيمارى ايدز بلهور مستقيم و غيرمستقيم با صرف هزينه مادى مانى

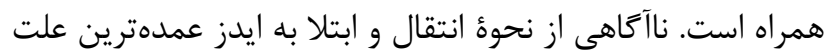

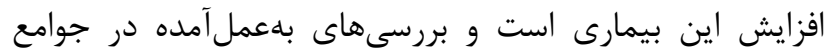
مختلف نشاندهنده سطح آكاهى متفاوت افراد نسبت به ايدز

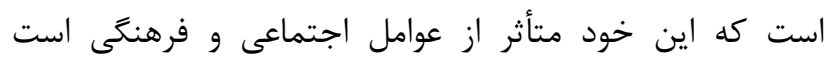

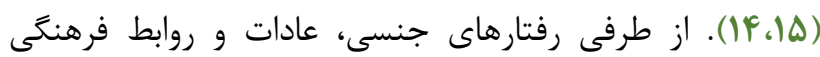
نقش اساسى در بِيشگيرى از آن بازى مى كنند (1). شواهدى در دست است كه نشان مىدهد عوامل اجتماعى و فرهنكى تأثيرى قابل ملاحظهاى بر ابتلاى به ايدز دارند (IV،IN)

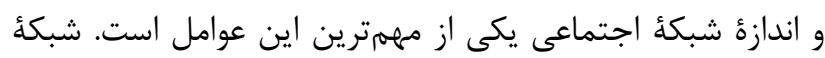
اجتماعى مجموعهاى ناتهى از ترهها و رابطهاى (احتمالاً تهى إنى تعريفشده براى اين تاركها و مجموعهاى از زيوندها است.

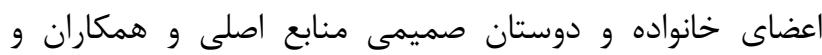
روحانيون و سايرين منابع ثانوى شبكةٔ اجتماعىاند. يرداختن به

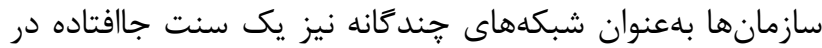
مطالعات اجتماعى است (19). 


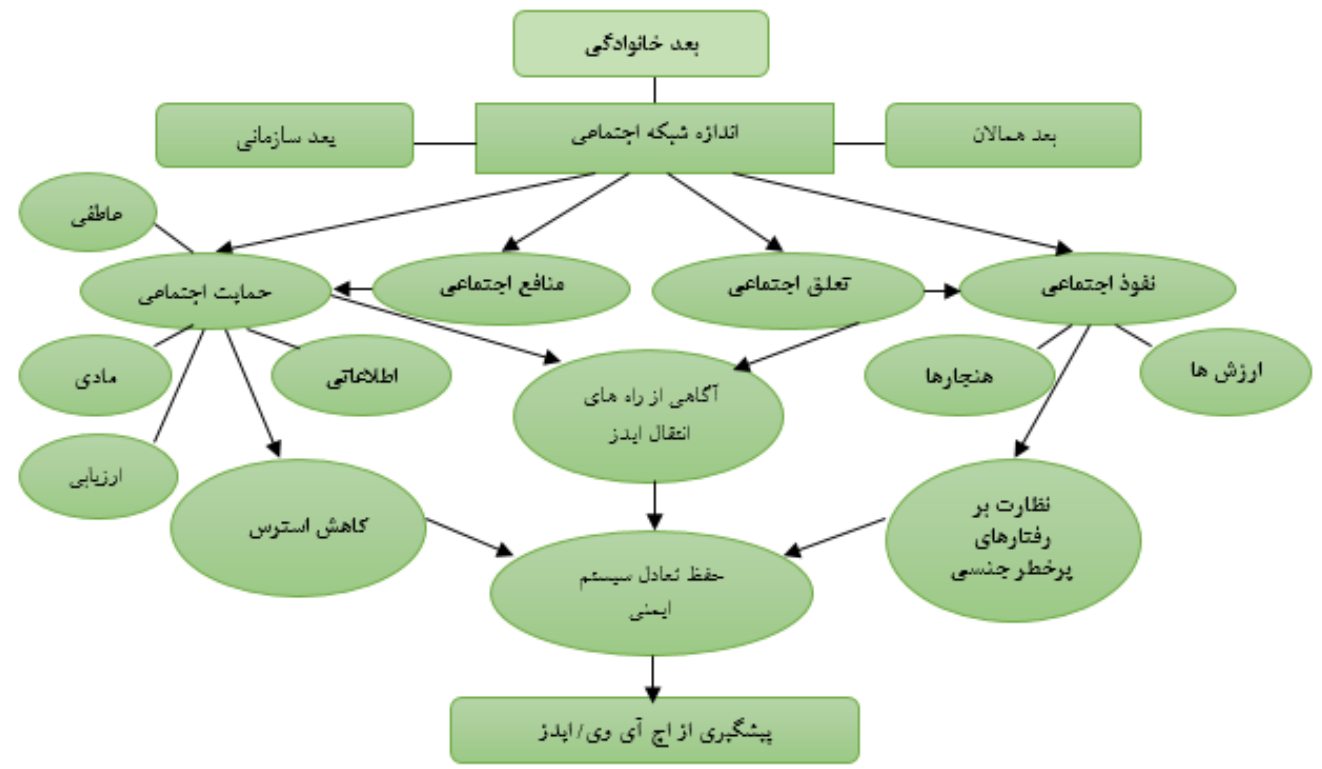

شكل ا. مدل مفهومى رابطُ شبكههاى اجتماعى و احتمال وقوع آج آى وى / ايدز در مبتلايان جنسى

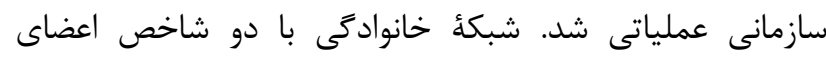

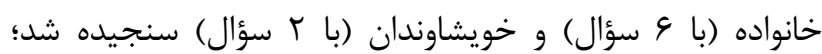

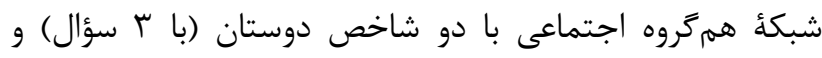

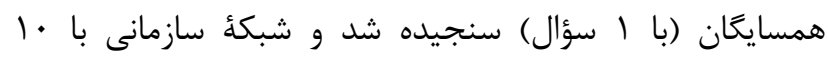

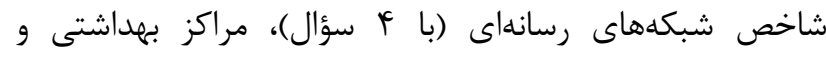

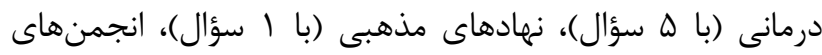

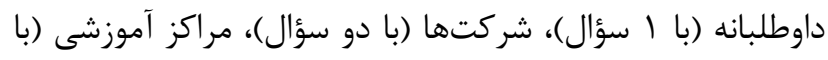

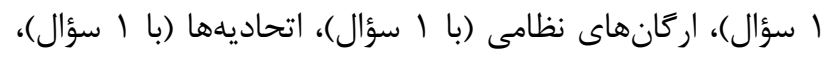

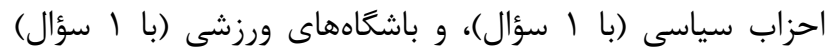

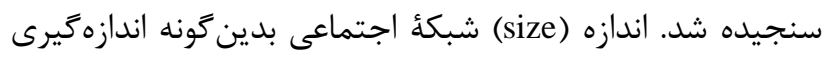

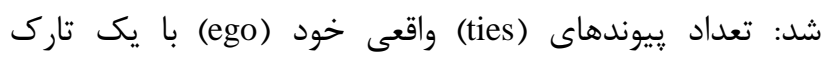
(vertex) بخش اطلاعات دموكرافيك و اندازه شبكة اجتماعى تهيه شداصند.

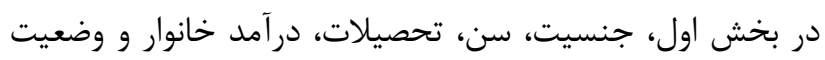

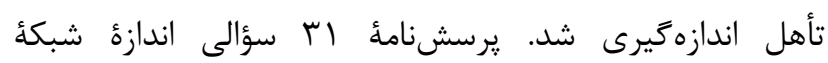

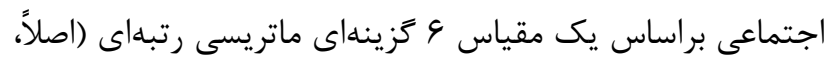

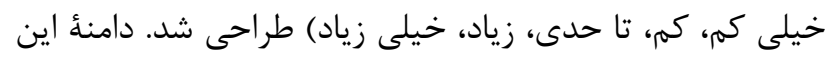

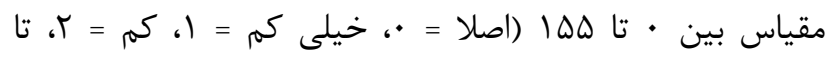

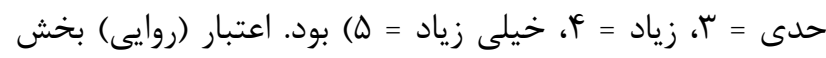

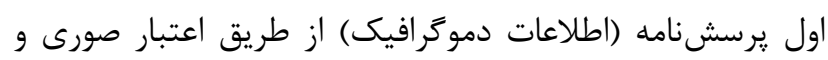
محتوايى (توسط ب نفر از متخصصان جمعيتشناسى) و اعتبار

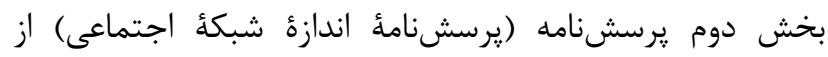

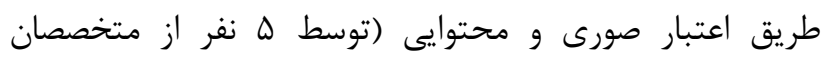

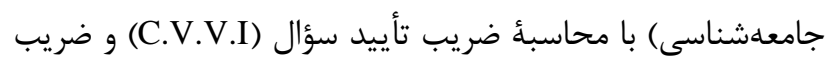

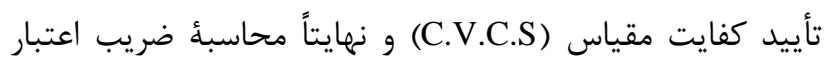

روش بررسى

يزوهش حاضر يك مطالعأ توصيفى و مقطعى است.

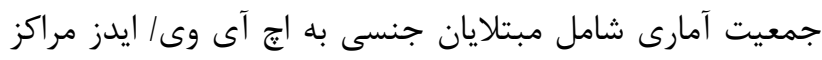

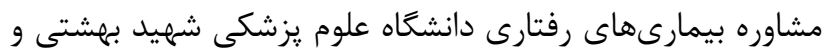

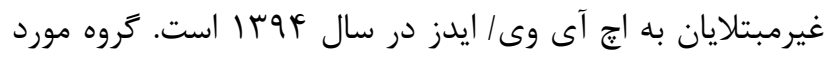

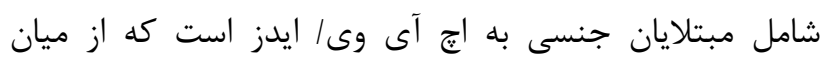

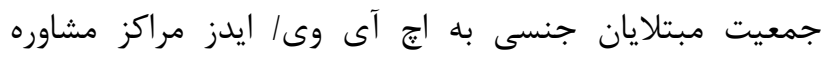

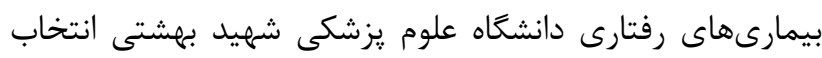

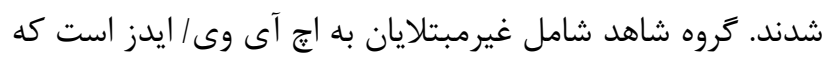

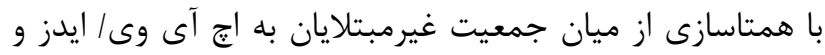

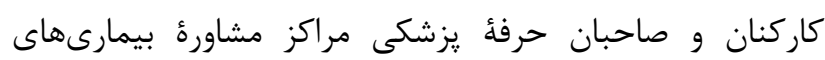

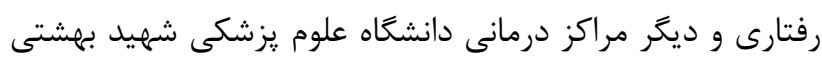

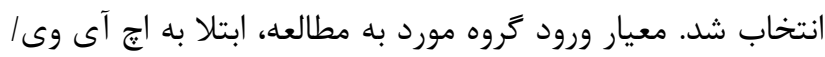

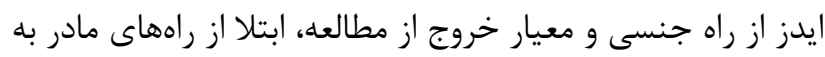

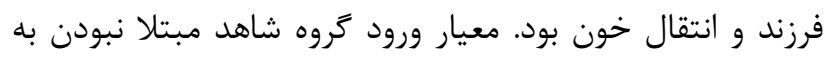

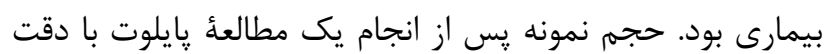

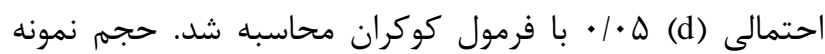

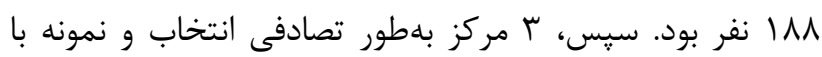

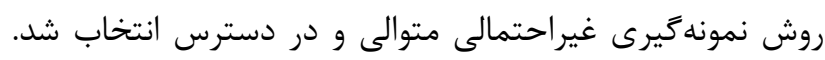

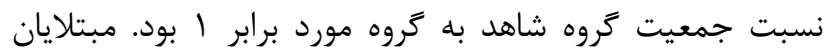

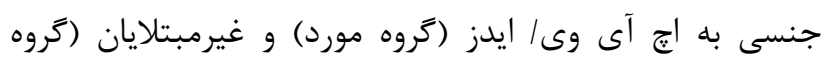

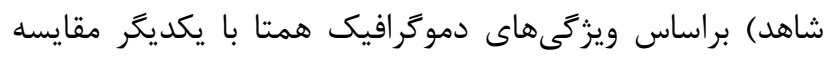

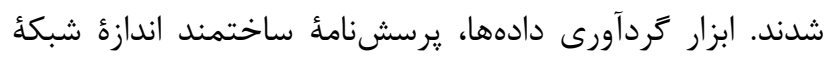

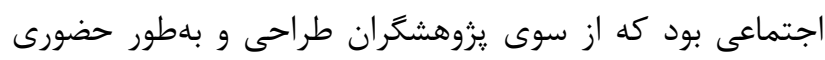

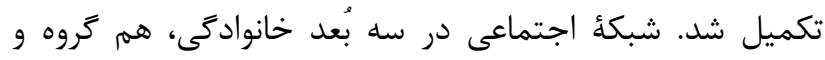


SPSS دادهاى كردآورىشده با به كاركيرى نرمافزار آمارى

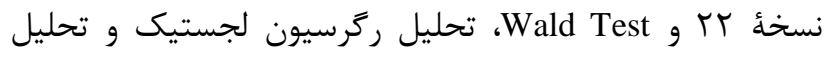
افتراقى مورد تجزيهوتحليل قرار گرفت. رضايت آكاهانه، رازدارى و ناشناسى بهعنوان ملاحظات اخلاقى يزوهش رعايت شدند.

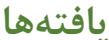

بنا بر نتايج جدول ا، اكثر مبتلايان به آج آى وى/ ايدز

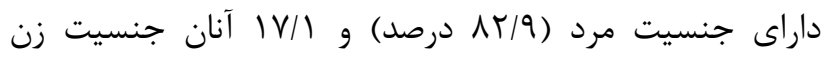

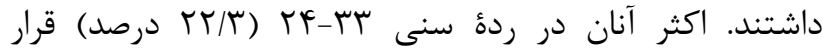

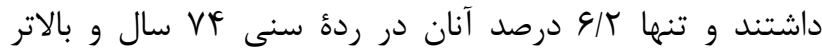

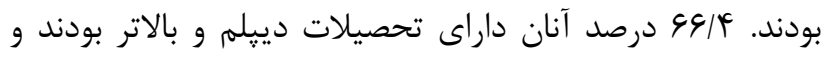

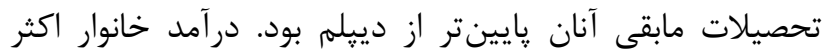
مبتلايان اله هزار تا ا ميليون تومان بود. اكثر آنان متأهل

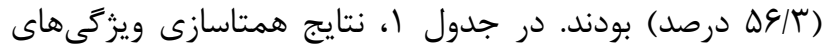

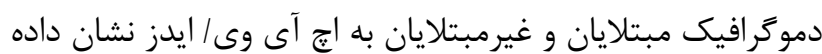

محتوايى براى رسيدن به حد نصاب سنجيده شد. براى ارزيابى

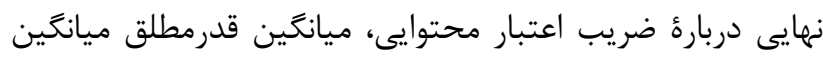
ضرايب تأييد سؤال و ميانكين ضرايب تأيب أيبد كفايت مقايت مقياس

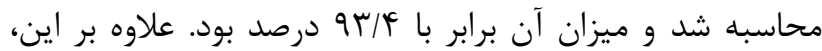

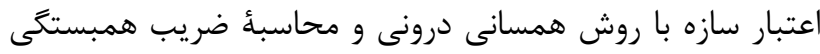

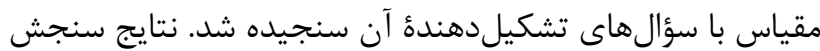

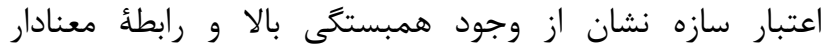

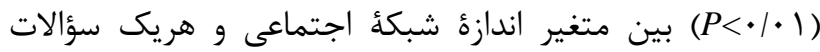

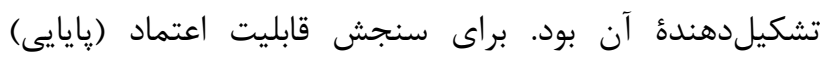
يرسشنامة اندازه شبكؤ اجتماعى از ضريب آلفاى كرونباخ استفاده

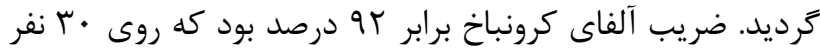

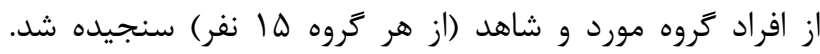

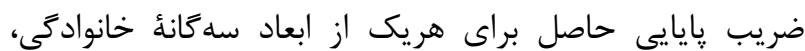

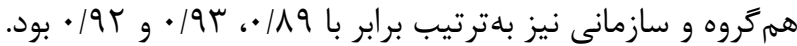

شده است.

جدول ا. توزيع فراوانى ويزگكىهاى دموكر افيك همتاشده

\begin{tabular}{|c|c|c|c|c|}
\hline \multicolumn{2}{|c|}{ غير مبتلايان } & \multicolumn{2}{|c|}{ مبتلايان } & \multirow{2}{*}{ متغير هاى دموكرافيك } \\
\hline درصد فراوانى & فراوانى & درصد فراوانى & فراوانى & \\
\hline & & & & جنس \\
\hline$\Lambda T / F$ & $1 \Delta \Delta$ & $\Lambda r / 9$ & 109 & مرد \\
\hline \multirow[t]{2}{*}{ IV/Q } & r & $|V /|$ & rt & زن \\
\hline & & & & سن \\
\hline$\Lambda / \Delta$ & 19 & $N / \Delta$ & 19 & سז و كمتر \\
\hline$r r / F$ & pq & $T r / r$ & gr & $r F-r r$ \\
\hline $\mid f / \Lambda$ & rA & $10 / 9$ & $r$. & $r F-F r$ \\
\hline $\mid \mathrm{V} / \cdot$ & rt & $|N /|$ & re & $F F-\Delta r$ \\
\hline $\mid \mathrm{V} / \cdot$ & rt & $10 / 9$ & r. & $\Delta F-g r$ \\
\hline $\mid \pi / \Lambda$ & re & $\mid r / \Lambda$ & re & $g q-V r$ \\
\hline \multirow[t]{2}{*}{$9 / \pi$} & IT & $9 / \pi$ & IT & و و بالاتر VF \\
\hline & & & & تحصيلات \\
\hline$r r / q$ & GT & r & st & پايينتر از ديبلم \\
\hline \multirow[t]{2}{*}{$9 \mathrm{~V} / \cdot$} & Irs & $99 / 4$ & $1 r \Delta$ & دييلم و بالاتر \\
\hline & & & & در آمد خانوار \\
\hline$r q / r$ & $\Delta \Delta$ & $r N / 1$ & $\Delta r$ & كمتر از ••ه هزار تومان \\
\hline$F F / 9$ & $\Delta F$ & $r \& / T$ & $\wedge \vee$ & 1.ه هزار تا ا ميليون تومان \\
\hline \multirow[t]{2}{*}{ rघ/. } & $4 q$ & $r \Delta / \Delta$ & $\psi \wedge$ & بالاتر از 1 ميليون تومان \\
\hline & & & & وضعيت تأهل \\
\hline rq/V & $\Delta \varphi$ & TN/V & $\Delta F$ & مجرد \\
\hline$\Delta \varphi / T$ & 1.4 & $\Delta s / \Gamma$ & 1.9 & متأهل \\
\hline$f / r$ & $\wedge$ & $F / V$ & 9 & همسر فوتشده \\
\hline$\Lambda / \Delta$ & 19 & $9 / \Delta$ & 11 & همسر جداشده \\
\hline $1 / \pi$ & r & $\cdot / 1$ & 1 & هركز ازدواجنكرده \\
\hline
\end{tabular}


سازمانى شبكأ اجتماعى مبتلايان به اج آى وى/ ايدز و غيرمبتلايان

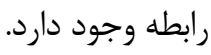

در جدول r مشاهده مىشود كه شدت رابطؤ مجموع ابعاد اندازه شبكؤ اجتماعى مبتلايان به آج آى وى/ ايدز و غيرمبتلايان

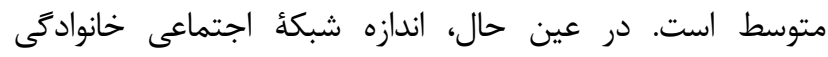
بيشترين سهم رادر تبيين تفاوت دو كروه مبتلايان به اتج آى وى آنا

$$
\text { ايدز و غيرمبتلايان دارد. }
$$

همانطور كه نتايج جدول r نشان مىدهد، ميانخين اندازه

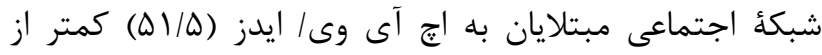

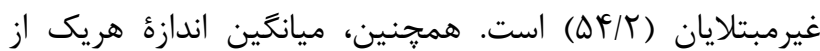

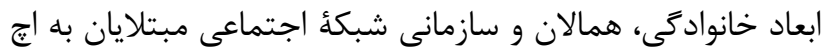

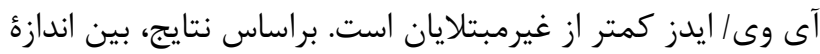

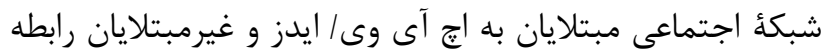

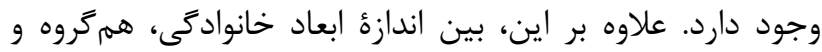

جدول r. توزيع فراوانى ويثزى هاى دموكرافيك همتاشده

\begin{tabular}{|c|c|c|c|c|}
\hline \multicolumn{2}{|l|}{ غير مبتلايان } & \multicolumn{2}{|l|}{ مبتلايان } & \multirow{2}{*}{ متغير اصلى و ابعاد آن } \\
\hline انحرافمعيار & ميانخين & انحرافمعيار & ميانخين & \\
\hline $1 / 9$ & $\Delta F / T$ & $9 / V$ & $\Delta 1 / \Delta$ & اندازه شبكةٔ اجتماعى \\
\hline 919 & $r \Delta / V$ & $\Delta / 9$ & ( - l & اندازه شبكة اجتماعى خانوادگى \\
\hline$V / f$ & $\Delta 9 / 9$ & $F / V$ & $\Delta \mathrm{V} / \mathrm{I}$ & اندازه شبكة اجتماعى همالان \\
\hline $\mathrm{V} / \mathrm{V}$ & rq/q & $9 / \pi$ & re/V & اندازه شبكئ اجتماعى سازمانى \\
\hline \multicolumn{5}{|c|}{ جدول r. نتايج تحليل افتراقى، ضريب افتراقى و همبستكى كانونى } \\
\hline همبستگى كانونى & & ضريب افتراقى & & ابعاد متغير اصلى \\
\hline \multirow{3}{*}{$\cdot / F F$} & & $r r / q$ & & اندازهُ شبكةٔ اجتماعى خانوادكى \\
\hline & & एब/G & & اندازهُ شبكة اجتماعى همالان \\
\hline & & $r 1 / f$ & & اندازه شبكةُ اجتماعى سازمانى \\
\hline
\end{tabular}

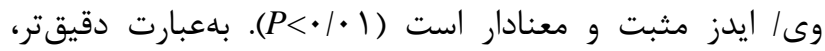

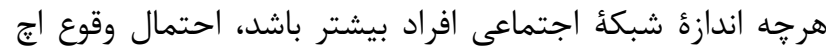

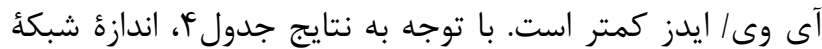
اجتماعى مبتلايان و ابعاد آن قابليت ورود به مدل لوجيت (معادله بهينهُ ركرسيون لجستيك) را دارد.
براساس نتايج جدول لُ، نسبت برترى اندازه شبكة اجتماعى

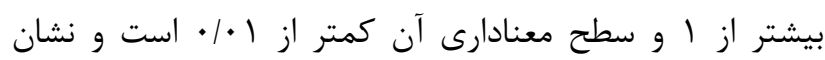

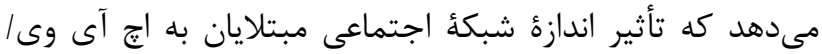

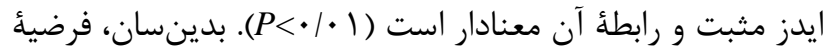

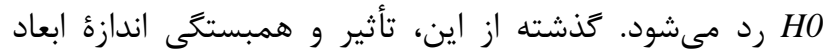

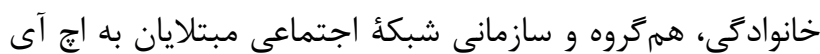

جدول ؟. نتايج آزمون والد و تحليل ركر سيون لجستيك شبكةٔ اجتماعى و ابعاد آن

\begin{tabular}{|c|c|c|c|c|c|}
\hline مقدار ثابت & ضريب ركرسيون & 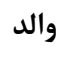 & معنادارى & نسبت برترى (OR) & متغير اصلى و ابعاد آن \\
\hline$T / M F$ & $\cdot / \cdot r$ & $\cdot / V r$ & $\cdot 1 \cdot{ }^{* *}$ & $1 / 19$ & اندازهُ شبكئ اجتماعى \\
\hline r/gF & $\cdot 1 \cdot \mathrm{F}$ & $\cdot / \Delta V$ & $\cdot / .^{* *}$ & $1 / 11$ & اندازهُ شبكهُ اجتماعى خانوادكى \\
\hline$T / T \Delta$ & $\cdot / \cdot r$ & $\cdot 119$ & $\cdot / .^{* *}$ & $1 / r \mu$ & اندازهٔ شبكةٔ اجتماعى همالان \\
\hline $\mathrm{F} / \Lambda \Lambda$ & $\cdot 1 \cdot 9$ & $\cdot \mid \Delta \Lambda$ & $\cdot / .^{* *}$ & $1 / 1 F$ & اندازءٔ شبكةٔ اجتماعى سازمانى \\
\hline
\end{tabular}

Notes: $* P$-value $<0.05 ; * * P$-value $<0.01$

رفتارى دانشعاه علوم يزشكى شهيد بهشتى بود. نتايج نشان داد

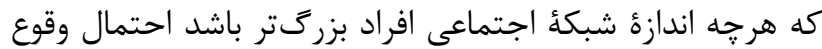

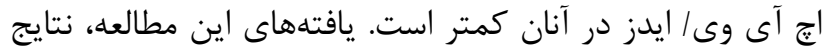

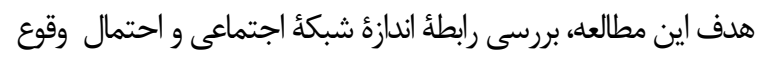

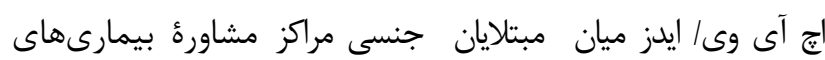


اجتماعى ابزارى است براى تحكيم منابع و دفاع در برابر از دست دادن منابع. در اين رابطه ب نوع نفع مطرح است: سلامت داريت

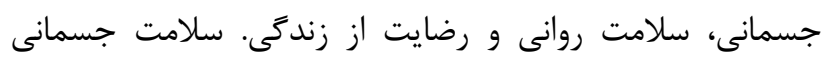

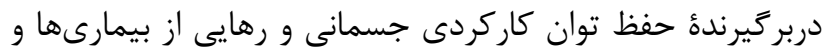

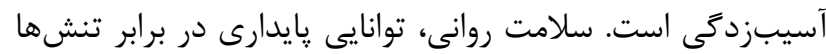
و حفظ تعادل عقلى و احساسى را منعكس مى كند. رضايت از زندكى نيز نشانكر خوشبينى و رضايت از عرصههاى مختلف

زندكى مانند ازدواج، كار، جامعه و محيطزيست است (ج) (؟). محدوديت اصلى اين مطالعه بىاطلاعى بيماران از راههاى

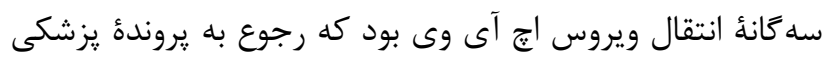

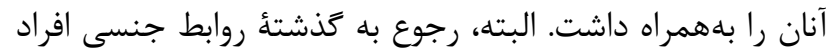
ملاحظات اخلاقى دوجندان را مطرح مىساخت.

$$
\text { نتيجه كيرى نات احلى دوجن }
$$

شبكة اجتماعى مىتواند باعث افزايش حمايت اجتماعى، نفوذ

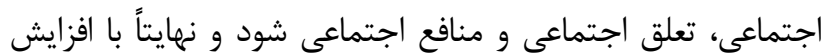

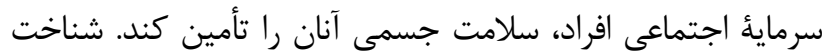
بيشتر اين تعيينكنندة اجتماعى سلامت و بيمارى عاملى مهرم در

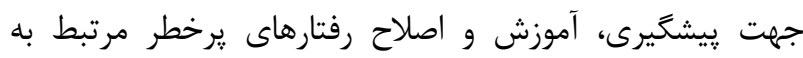
بيمارى ايدز است. شناخت انواع شبكههاى اجتماعى و مسيرهاى

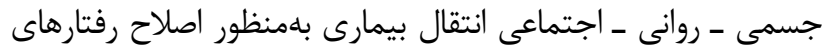

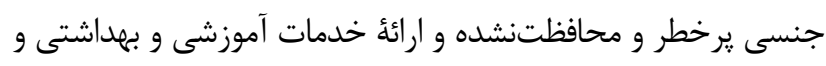
ارتقاى ميزان آكاهى افراد از نحؤ انتقال اين بيمارى از راه شبكههاى

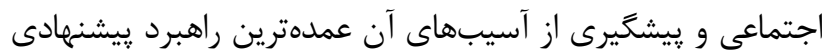
است. تكتك افراد جامعه بايد در اين راه سهيم باشند تا با فعاليت آنايت

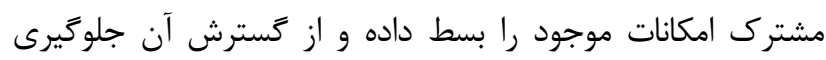
كرد. يزوهشهاى آتى بايد درصدد بررسى ديخر مسيرهاى انتقال اج

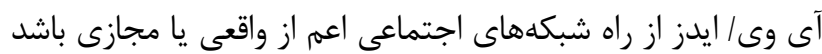
و اين امر نيازمند يزوهش آدهاى بيشتر است.

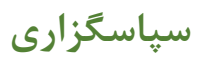

نويسندكان مقاله از يزشكان، يرستاران و كاركنان دانشكاه علوم

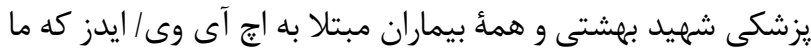
را در انجام اين مطالعه يارى كردند، كمال تشكر و قدردانى را دارند.

$$
\text { تعارض در منافع }
$$

بين نويسندكان تعارضى در منافع كزارش نشده است.
تحقيق O’Brien و همكارانش را تأييد مىكند كه نشان داد روابط اجتماعى و تجربأ ذهنى حضور در شبكدهاى اجتماعى يك

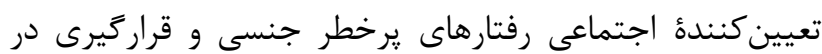
معرض خطر ابتلا به ايدز در ميان افراد است (بّ). نتايج اين تحقيق، يافتههاى يزوهش Miller و Paone را تأييد مى كند كه

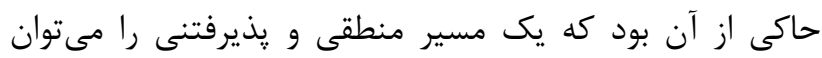
فرض كرفت كه براساس آن، ويزگى هاى شبكأ اجتماعى احتمال قراركيرى در معرض خطر اج آى وى را كاهش مىدهد (YF). نتايج اين مطالعه، يافتههاى Klovdahl و همكارانش را تأييد

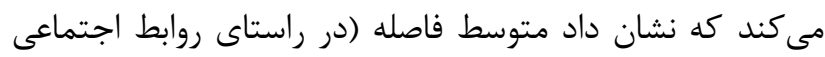

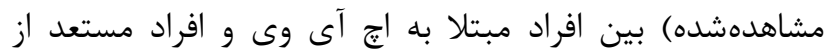
مركز شبكؤ اجتماعى ץ گام بود (Yه).

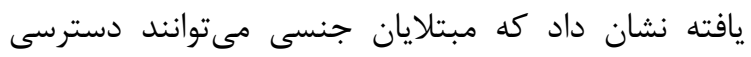

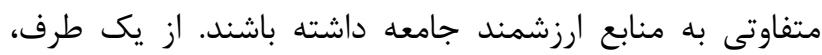

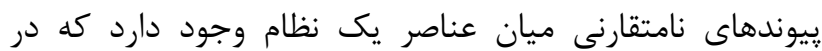

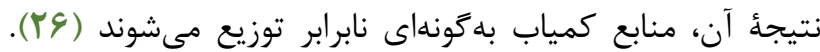

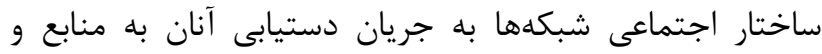

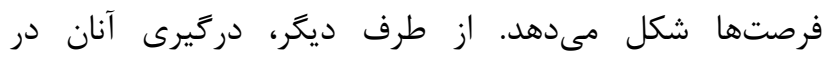
شبكههاى اجتماعى مختلف از جمله شبكههاى خانوادكى،

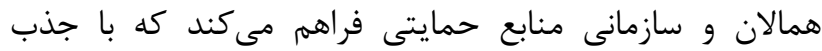

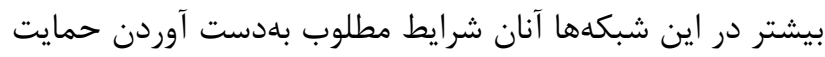

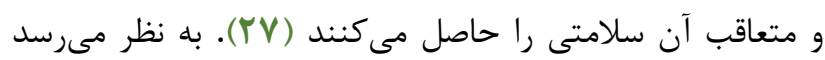
هر جه اين شبكدهاى اجتماعى در جامعأ مبتلايان جنسى فشردهتر

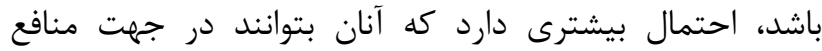

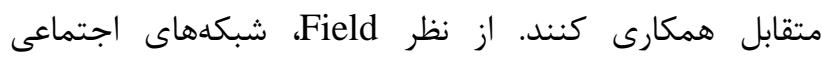
مى توانند مساعدت مادى ملموسى را براى فرد فراهم كنند كه باعث كاهش اضطراب شود، هنجارهاى بهداشتى را تقويت كند و فرد بهتر بتواند براى استفاده از خدمات درمانى اعمال نفوذ كند

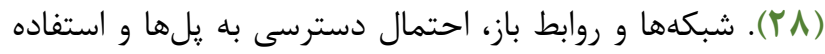
از آنها براى رسيدن به منابعى كه در حلقهُ اجتماعى فرد وجود ندارند و نيز دستيابى به منابع و منافع ابزارى را افزايش مى دهديد

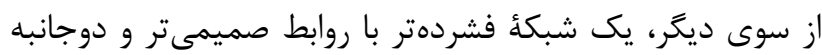

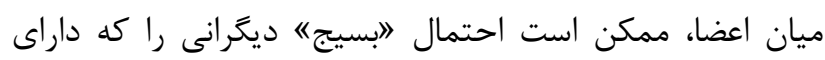

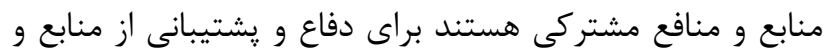
منافع عاطفى افزايش دهد.

شايد بتوان نتايج سرمايهَذارى مبتلايان جنسى در روابط و

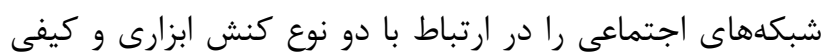
طبقهبندى كرد. در كنش ابزارى، سهونه نفع (بازگشت سرمايه) مطرح است: ثروت، قدرت و شهرت. در كنش كيفى، سرمائ 


\section{References}

1. Ahmadi H, Jamali M. Factors of Knowledge and Attitue Addict Prisoners to AIDS and its Solutions. Soc Sci Hum. 2006;2(47):1-8.

2. Tan JY, Huedo Medina TB, Warren MR, Carey MP, Johnson BT. A Meta-Analysis of the Efficacy of HIV/AIDS Prevention Interventions in Asia, 19952009. Soc Sci Med. 2012;75(4):676-87.

3. Gould WT. HIV/AIDS in developing countries. London: International Encyclopedia of Human Geography; 2009.

4. Ayranci U. AIDS Knowledge and Attitudes in a Turkish Population: an epidemiological study. BMC Public Health. 2005;5(1):95-105.

5. Hatami H, Afshari D, Almasi F, Rahimi M, Razavi M, Jahanbakhsh A. Medical Health and Social of HIV/AIDS. Kermanshah: Tagh-e-Bostan; 2004.

6. Ministry of Health and Medical Education. Official report. Tehran: Ministry of Health and Medical Education; 2015.

7. Kolahi AA, Rastegarpour A, Abadi AR, Nabavi M, Sayyarifard A, Sohrabi MR. The Knowledge and Attitudes of a Female at-risk Population Towards the Prevention of AIDS and Sexually Transmitted Infections in Tehran. $\mathbf{J}$ Res Med Sci. 2011;16(11):1452-8.

8. Mozaffarzadeh S, Vahdaninia M. AIDS Literacy among Female Highschool Students: a crosssectional study from Iran. Payesh. 2008;7:173-80.

9. Lotfipur Rafsanjani SM, Ravari A, Akbarinasab J. Knowledge, Attitude and Practice of Non-medical Student to the Ways of Transmission and Prevention of AIDS in Rafsanjan. Nurs Res. 2011;22(6):31-9.

10. Piot P, Coll Seck AM. International Response to the HIV/AIDS Epidemic: Planning for Success. Bull World Health Organ. 2001;79(12):1106-12.

11. Stansbury JP, Sierra M. Risks, Stigma and Honduran Garífuna Conceptions of HIV/AIDS. Soc Sci Med. 2004;59(3):457-71.

12. Alubo O, Zwandor A, Jolayemi T, Omudu E. Acceptance and Stigmatization of PLWA in Nigeria. AIDS Care. 2002;14(1):117-26.

13. Wang B, Li X, Barnett D, Zhao G, Zhao J, Stanton B. Risk and Protective Factors for Depression Symptoms among Children Affected by HIV/AIDS in Rural China: a structural equation modeling analysis. Soc Sci Med. 2012;74(9):1435-43.

14. Mwambete KD, Mtaturu Z. Knowledge of Sexually Transmitted Diseases among Secondary School Students in Dar es Salaam, Tanzania. Afr Health Sci. 2006;6(3):165-9.
15. Jenkins CA, Arobalino D. HIV/AIDS in the Middle East and North Africa. Tehran: Shahid Beheshti University of Medical University; 2008.

16. Izdebski Z, Małyszkom M. Knowledge and Beliefs about HIV/AIDS. Impact of knowledge on having risky sexual behaviors among men who use methadone and among men who use drugs intravenously. HIV \& AIDS Review. 2012;11(3):65-70.

17. Rahmati Najarkolaei F. Niknami Sh, Amin Shokravi F, Ahmadi FA, Tavafian SAS, Hajizadeh E. Individual Factors Predisposing Hiv/Aids High Risk Behaviors: a qualitative study. Payesh. 2011;10(2):205-15.

18. Abdulraheem IS, Fawole OI. Young People's Sexual Risk Behaviors in Nigeria. J Adolesc Res. 2009;24(4):505-27.

19. Bruggeman J. Social networks: an introduction. London: Routledge; 2008.

20. Mahat G, Scoloveno MA, Scoloveno R. HIV/AIDS Knowledge, Self-Efficacy for Limiting Sexual Risk Behavior and Parental Monitoring. Journal of Pediatric Nursing. 2016;29;31(1):e63-9.

21. Lin N. Building a Network Theory of Social Capital. Connetions. 1999;22(1):28-51.

22. Hawe P, Shiell A. Social Capital and Health Promotion: a review. Soc Sci Med. 2000;51(6):87185.

23. O'Brien K, Wortman CB, Kessler RC, Joseph JG. Social Relationships of Men at Risk for AIDS. Soc Sci Med. 1993;36(9):1161-7.

24. Miller M, Paone D. Social Network Characteristics as Mediators in the Relationship between Sexual Abuse and HIV Risk. Soc Sci Med. 1998;47(6):76577.

25. Klovdahl AS, Potterat JJ, Woodhouse DE, Muth JB, Muth SQ, Darrow WW. Social Networks and Infectious Disease: the Colorado Springs Study. Soc Sci Med. 1994;38(1):79-88.

26. Ritzer G. Modern sociological theory. 7nd ed. New York: McGraw-Hill; 2008.

27. Mohseni Tabrizi AR. Theories in social pscychology. Tehran: University of Tehran; 2014.

28. Field J. Social capital. 2nd ed. London: Routledge; 2008.

29. Lin N. Social capital: A theory of social structure and action. Cambridge: Cambridge University Press; 2001. 